\title{
Systematic Approach to Prosthetic Rehabilitation of a Severely Worn Dentition: A Case Report
}

Roodabeh Koodaryan ${ }^{1}$, Ali Hafezeqoran ${ }^{1}$

1. Department of Prosthodontics, Faculty of Dentistry, Tabriz University of Medical Sciences, Tabriz, Iran

\begin{abstract}
Management of tooth wear has been subject of increasing interest from both preventive and restorative points of view. This article describes the systematic rehabilitation of a 60 -year-old man with severe worn dentition and several missing teeth. The treatment was to restore the dentition with cast posts and cores and porcelain-fused-to-metal (PFM) restorations. The treatment success was ensured with the equalintensity centric occlusal contacts on all teeth, the development of anterior guidance and posterior disclusion in harmony with functional border movements.
\end{abstract}

Keywords: Porcelain-fused-to-metal (PFM) restorations: Occlusal plane; Occlusal vertical dimension (OVD); Prosthodontic rehabilitation; Tooth wear

\section{Introduction}

Severe tooth wear is an important clinical problem that threatens dentition and masticatory function. Three basic physical and chemical mechanisms (stress, friction and corrosion) result in tooth surface loss. Tooth wear can be classified as attrition, abrasion, and erosion depending on its cause and any combination of the aforementioned factors may result in tooth wear (1). The management of tooth wear, especially attrition, is a challenge in the prosthodontics treatment, from both preventive and restorative points of view. Long treatment time and lack of clarity in the therapy objectives make the rehabilitation process complex. Therefore, successful and predictable treatment outcome depends on the systematic approach for managing the tooth wear $(2,3)$. The steps in the treatment approach of these cases include comprehensive examination, diagnostic articulated study casts and wax-up, precise treatment planning and sequencing of various steps and cautious execution of the treatment plan $(4,5)$. This case report presents a systematic approach for the prosthodontic management of an old male patient with severely worn dentition and an uneven occlusal plane.

\section{Case presentation}

\section{Corresponding author:}

Ali Hafezeqoran

Department of Prosthodontics, Faculty of Dentistry, Tabriz University of Medical Sciences, Tabriz, Iran Tel: +989141142055 E-mail: hafezeqoran@gmail.com

Receive date: 2015-03-28| Accept date: 2015-04-29| Publish date: 2015-05-03

DOI: 10.7575/aiac.abcmed.15.03.03.10

\section{A. I}




\section{Examination}

A 60-year-old man was referred to the Department of Prosthodontics, Faculty of Dentistry, Shahid Beheshti University of Medical Sciences, Iran, with a chief complaint of inability to chew. He was eager to restore unaesthetic worn teeth in addition to the replacement of missing teeth (Figure 1). Clinical and radiographic examinations revealed severe anterior attrition with minimal posterior wear and also an uneven occlusal plane was apparent. The cause of the severe wear was parafunction including clenching, grinding, and lack of posterior occlusion due to missing mandibular posterior teeth. No periodontal pocketing and abnormal tooth mobility was noted and the oral hygiene was acceptable.

\section{Preoperative planning}

Anterior deprogramming device was used to guide the mandible to centric relation by bilateral manipulation. Study casts were obtained and mounted on a semi-adjustable articulator (Hanau $^{\mathrm{TM}}$ Modular Articulator, Whip Mix Corp., Louisville, KY) using centric relation occlusal records and a face bow transfer. Prior to waxing the case, a centric relation anterior index was made utilizing a pattern resin material (Duralay, Reliance Dental Mfg Co., Worth, IL). This index maintains the centric relation position at the desired vertical dimension of occlusion (VDO) during the preparation phase. An intraoral acrylic mock-up was performed to establish an ideal incisal plane which was communicated to the laboratory technician as an aid for full-mouth diagnostic wax up. The maxillary and mandibular study models were analyzed using Broadrick flag analyzer and modified if needed to establish a plane of occlusion with optimum curves of Spee and Wilson (Figure 2). After the diagnostic wax-up was completed, putty index was formed that would later help with fabricating the provisional restorations.

\section{Treatment planning}

The treatment plan included full-coverage restorations on all teeth, and porcelain-fusedto-metal (PFM) restorations were preferred for a long-term predictability. As severe anterior teeth wear led to insufficient tooth length, root canal therapy of several worn teeth was performed for long term esthetic and functional restoration of the teeth.

The patient was scheduled for appointments to prepare the maxillary and mandibular arches. With the aid of centric relation index, two posterior bite records were made at the desired occlusal vertical dimension (OVD) utilizing a pattern resin material. These indices were used consecutively for the preparation of teeth and verifying clearance. Using these indices, the centric relation and vertical dimension were maintained. After completion of tooth preparation, provisional restorations were formed with temporary acrylic restoration material using putty templates of the diagnostic wax up. Provisional restorations were fabricated in three sections: two posterior sections from molar to first premolar and an anterior section from canine to canine (Figure 3).

The provisional restorations were equilibrated to establish the maximum intercuspation in centric relation along with canine guidance and anterior coupling in protrusive guidance. Later, an occlusal bite record was taken. Impressions of the provisional restorations were made, and a facebow recording was taken of the maxillary provisionals. The maxillary and mandibular provisional models were mounted against each other using face bow transfer and the occlusal bite record consecutively. Later, a custom incisal guide table was established to reproduce the anterior guidance of the provisional restorations (Figure 4). This table delineates the shape of the lingual aspects and the path taken from the excursions. By moving the articulator 

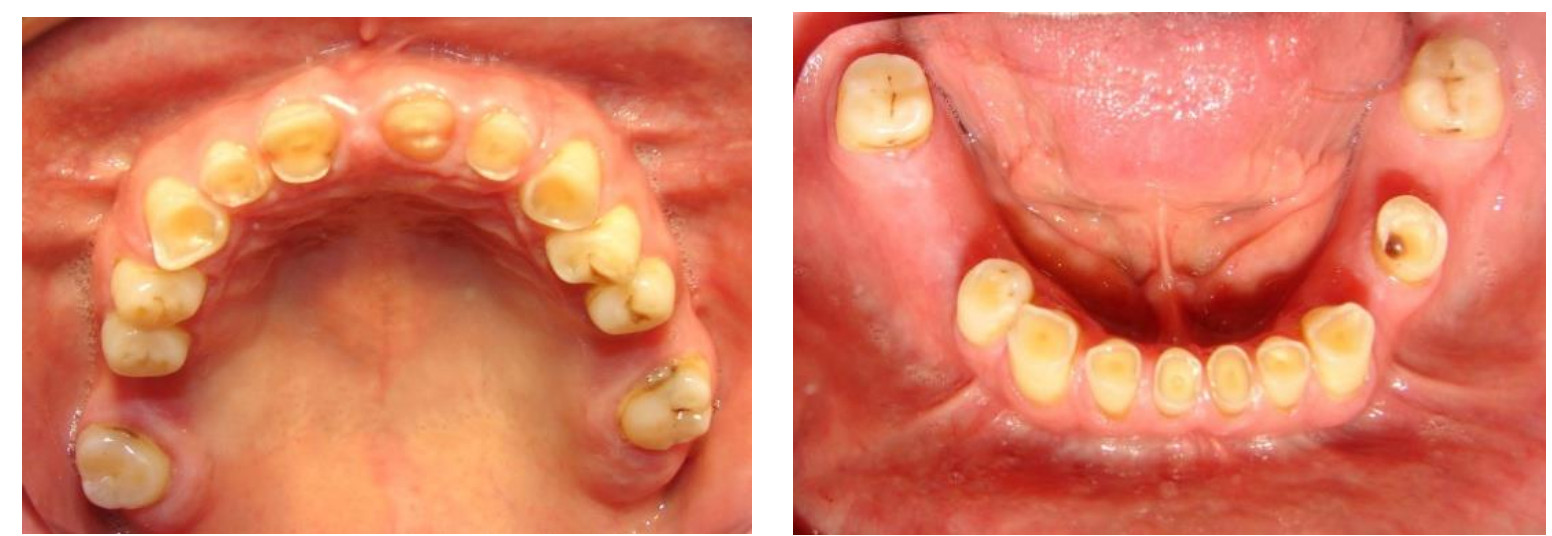

Figure 1: Preoperative view of the patient with severely worn dentition

pin, the protrusive and lateral excursions were recorded in a pattern resin on the flat guide table. Accompanied with the custom guide table, a putty template was made from the provisional restoration models to simulate the exact length and form for the final restorations.
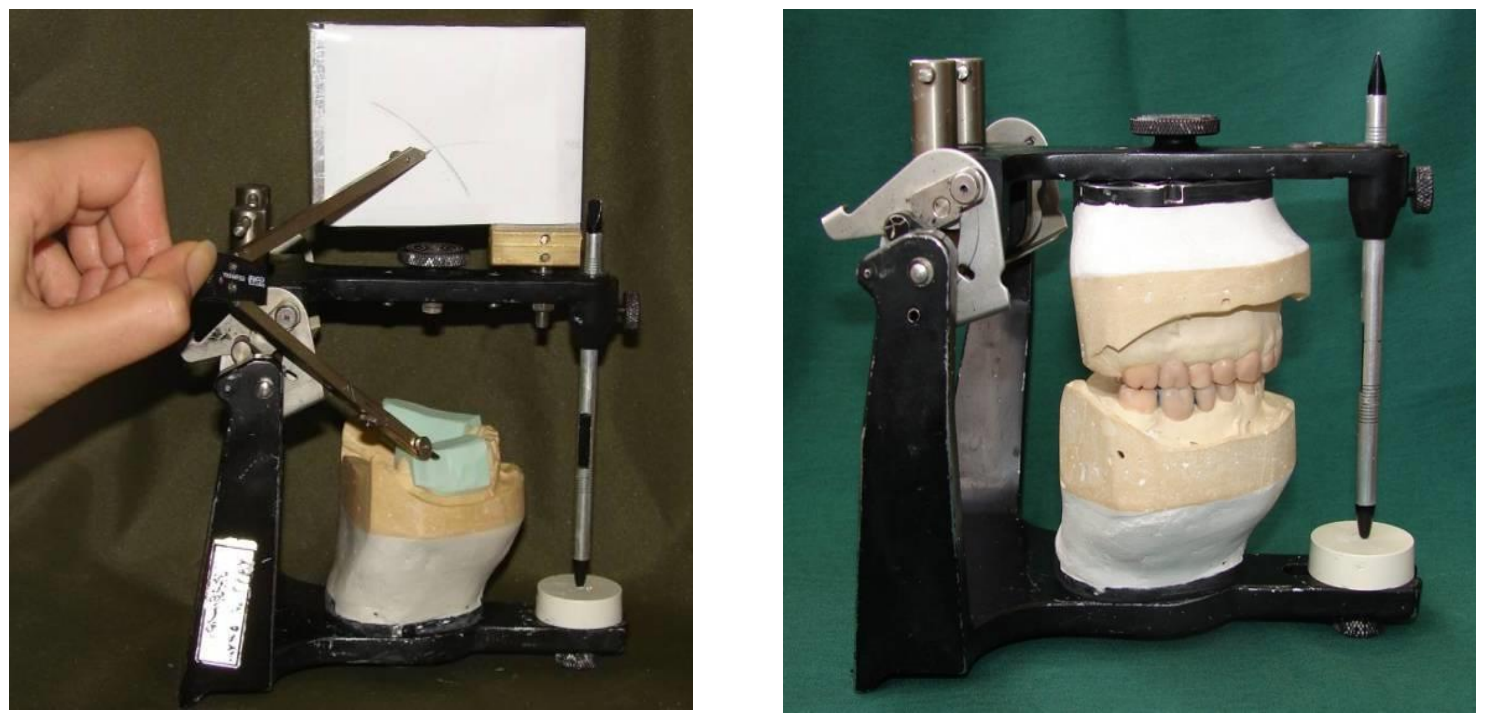

Figure 2: Study models were analyzed using Broadrick flag analyzer and modified if needed. Later, diagnostic wax up was done on the desired vertical dimension

The provisional restorations were used for three months, and esthetic, occlusion and patient tolerance were evaluated during this period. Following a three month period of evaluation, final impressions were made with a silicon impression material (Speedex, Coltene AG, Alstatten, Switzerland). Consequently, the provisional restorations were removed and replaced with the definite prostheses. Since the technician reproduced the contours of the provisional restorations, minimal adjustments were required during the appointment. Restorations were evaluated for aesthetics, occlusion, and phonetics and posterior disclusion on protrusion and canine guided occlusion were established on the restorations (Figure 5). 

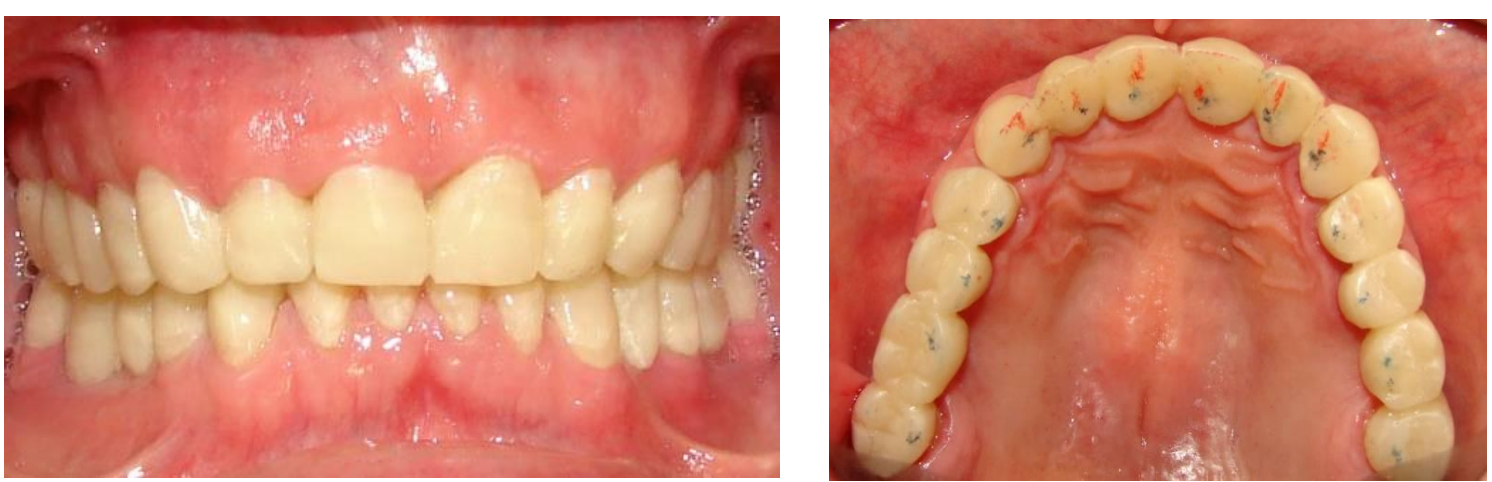

Figure 3: Provisional restorations were cemented and equilibration impression of them was later performed

\section{Discussion}

Esthetic and functional rehabilitation of severe wear cases is one of the greatest challenges in dentistry. However, the treatment planning process can be simplified if the rules for programmed treatment planning are precisely followed, starting with the estimation of the cause of wear (5).

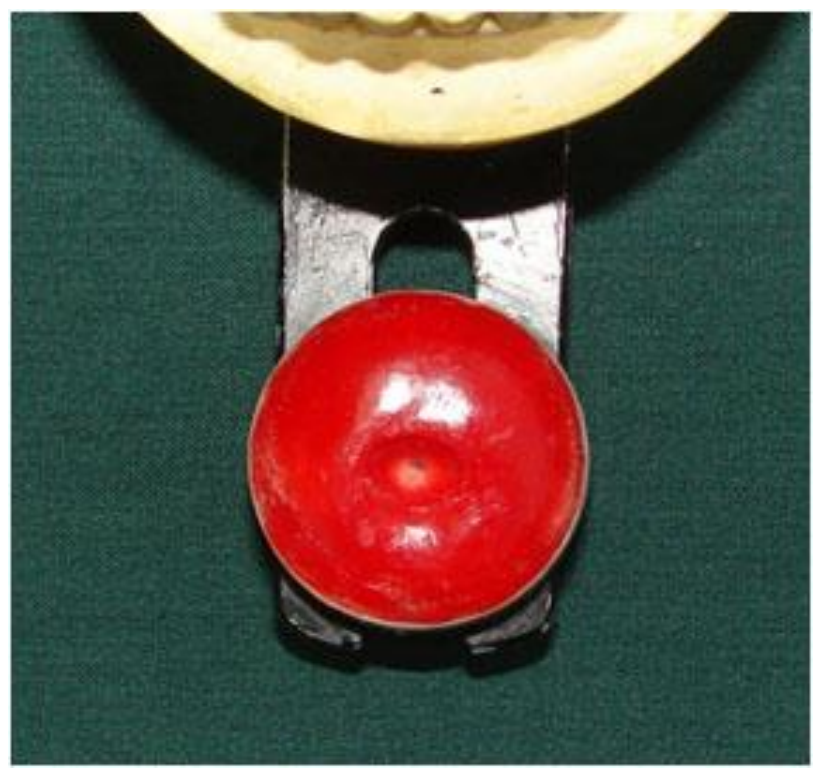

Figure 4: Customized incisal table was constructed

The occlusal wear in this case was attributed to parafunctional occlusal habit that started from his anterior teeth. Once the patient lost his anterior guidance, the posterior interferences developed. These interferences can activate the masticatory muscles, enabling the patient to generate more forces to grind remaining teeth more aggressively (6). For a long-term success, it is essential to consider occlusal and functional parameters. The development of proper anterior guidance and posterior disclusion ensures the maintenance of the rehabilitated occlusion. Equal-intensity centric occlusal contacts on all teeth and canine protected occlusal scheme prevents the destruction of the restorations $(7,9)$. In this scheme the posterior teeth prevent excessive contact of the anterior teeth in maximum intercuspation, and the canines disengage the posterior teeth in all mandibular excursive movements. In addition to occlusal scheme, an occlusal splint was fabricated for night wear reducing abnormal muscle activities.

\section{Summary}

This article presents a patient with severe tooth attrition and missing teeth. The prosthetic management of the case with porcelain to metal fused restorations was provided in detail and the treatment success was ensured with the development of anterior guidance and posterior disclusion. 

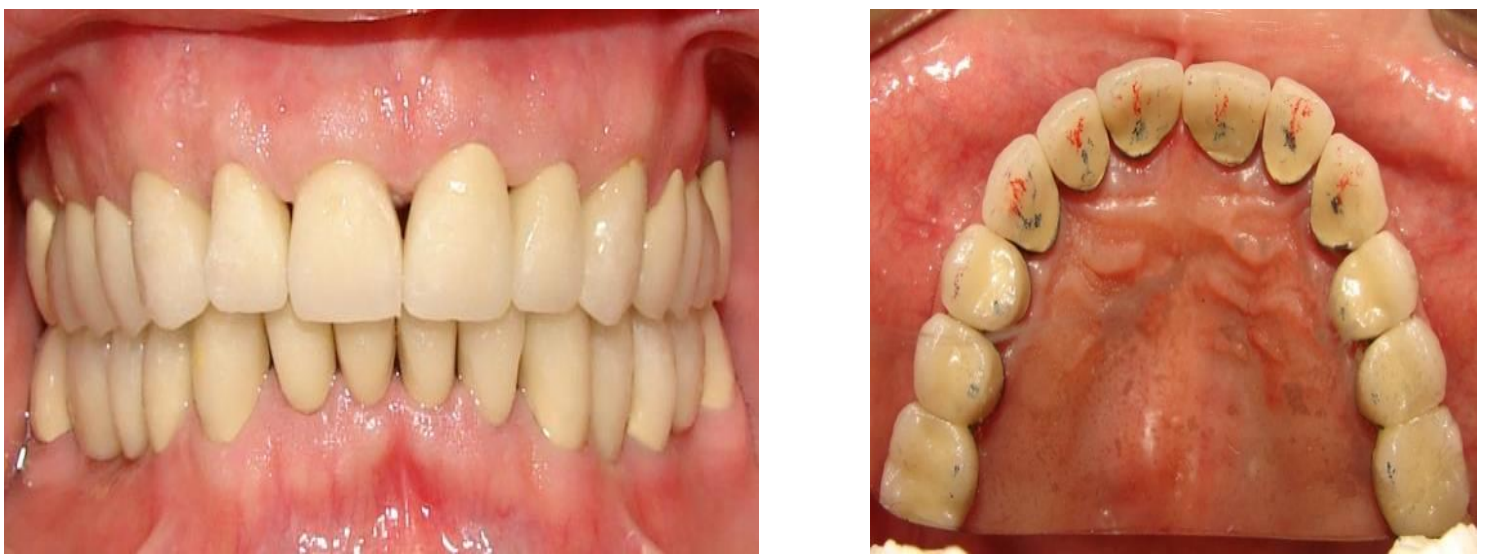

Figure 5: Definite restorations were delivered. Occlusal equilibration in centric relation established canine guidance

\section{References}

1. Dawson PE. Functional Occlusion: From TMJ to Smile Design. 1st ed. New York: Elsevier Inc.; 2008:430-52.

2. Lener J. A systematic approach to full-mouth reconstruction of the severely worn dentition. Pract Proced Aesthet Dent. 2008;20(2):81-7.

3. Bachhav VC, Aras MA. Altering occlusal vertical dimension in functional and esthetic rehabilitation of severely worn dentition. J Oral Health Res. 2010;1(1):2-8.

4. Doan PD, Goldstein GR. The use of a diagnostic matrix in the management of the severely worn dentition. J Prosthodont. 2007;16(4):277-81.

5. Song MY, Park JM, Park EJ. Full mouth rehabilitation of the patient with severely worn dentition: a case report. J Adv Prosthodont. 2010;2(3):106-10.

6. Nayar S, Aruna U, Hussain S, Bhuminathan S, Jayesh SR. Full mouth rehabilitation of a patient with severely attrited dentition. Ind J Multidiscip Dent. 2011;1(3):157-60.

7. Katsoulis J, Nikitovic SG, Spreng S, Neuhaus K, Mericske-Stern R. Prosthetic rehabilitation and treatment outcome of partially edentulous patients with severe tooth wear: 3-years results. J Dent. 2011;39(10):662-71.

8. Mahboub F, Fard EM, Geramipanah F, Hajimiragha H. Prosthodontic rehabilitation of a bruxer patient with severely worn dentition: a clinical case report. J Dent Res Dent Clin Dent Prospects. 2009;3(1):28-31.

9. Nayakar RP. Esthetic rehabilitation of severely worn dentition: a functional and prospective approach. Int J Dent Clin.2011;3(4):54-5. 